\title{
Impact of Inflammatory Response Modifiers on the Incidence of Hospital-Acquired Infections in Patients with COVID-19
}

Fernanda Meira · Estela Moreno-García · Laura Linares · Irene Macaya · Adria Tomé · Marta Hernández-Meneses • Laia Albiach • Laura Morata • Laura Letona • Marta Bodro • Alberto Cózar-Llistó • Celia Cardozo • Mariana Chumbita $\cdot$ Cristina Pitart · Juan Ambrosioni · Verónica Rico $\cdot$ Daiana Agüero $\cdot$ Pedro Puerta-Alcalde Nicole Garcia-Pouton · Francesc Marco • Carolina Garcia-Vidal • Alex Soriano (D) · José Antonio Martínez

Received: February 24, 2021 / Accepted: May 28, 2021 / Published online: June 11, 2021

(C) The Author(s)

\section{ABSTRACT}

Introduction: The study aim was to assess the influence of inflammatory response modifiers, including anti-interleukin-6 (IL-6) biologics and corticosteroids, on the incidence of hospitalacquired infections in patients with coronavirus disease 2019 (COVID-19).

Methods: Case-control study performed at a university hospital from February 26 to May 26, 2020. Cases were defined as patients with COVID-19 who developed hospital-acquired infections. For each case, two controls were selected among patients without infections. Cases and controls were matched obeying three criteria in a hierarchical sequence: length of

Supplementary Information The online version contains supplementary material available at https:// doi.org/10.1007/s40121-021-00477-9.

F. Meira · E. Moreno-García · L. Linares · I. Macaya - A. Tomé · M. Hernández-Meneses · L. Albiach · L. Morata - L. Letona - M. Bodro - A. Cózar-Llistó . C. Cardozo - M. Chumbita · J. Ambrosioni · V. Rico - D. Agüero · P. Puerta-Alcalde - N. Garcia-Pouton · C. Garcia-Vidal · A. Soriano $(\varangle) \cdot$ J. A. Martínez Department of Infectious Diseases, Hospital Clinic of Barcelona, C/ Villarroel 170, 08036 Barcelona, Spain

e-mail: asoriano@clinic.cat

C. Pitart · F. Marco

Department of Microbiology, Hospital Clinic, University of Barcelona, ISGLOBAL, Barcelona, Spain hospital stay up until the first infection; comorbidity; and need for Intensive care unit (ICU) admission. Conditional logistic regression analysis was used to estimate the association of exposures with being a case.

Results: A total of 71 cases and 142 controls were included. Independent predictors for acquiring a hospital infection were chronic liver disease [odds ratio (OR) 16.56, 95\% CI $1.87-146.5, p=0.012]$, morbid obesity (OR $6.11,95 \%$ CI $1.06-35.4, p=0.043)$, current or past smoking (OR 4.15, 95\% CI 1.45-11.88, $p=0.008)$, exposure to hydroxychloroquine (OR $0.2,95 \%$ CI $0.041-1, p=0.053$ ), and invasive mechanical ventilation (OR 61.5, 95\% CI 11.08-341, $p \leq 0.0001)$.

Conclusions: Inflammatory response modifiers had no influence on acquisition of nosocomial infections in admitted patients with COVID-19. Hospital-acquired infections primarily occurred in the critically ill and invasive mechanical ventilation was the main exposure conferring risk.

Keywords: COVID-19; Inflammatory response modifiers; Nosocomial infections; SARS-CoV-2 


\section{Key Summary Points}

In patients with COVID-19 that received inflammatory response modifiers, the most common infections were ventilatorassociated respiratory tract infections (tracheobronchitis or pneumonia).

The majority of patients with COVID-19 treated with inflammatory response modifiers were in an intensive care unit when the first hospital infection was diagnosed.

In patients treated with inflammatory response modifiers, the main risk factors for acquiring a nosocomial infection were chronic liver disease, morbid obesity, current or past smoking, and invasive mechanical ventilation.

Inflammatory response modifiers had no influence on acquisition of nosocomial infections in admitted patients with COVID-19.

\section{DIGITAL FEATURES}

This article is published with digital features, including a summary slide, to facilitate understanding of the article. To view digital features for this article go to https://doi.org/10.6084/ m9.figshare.14610504.

\section{INTRODUCTION}

Severe coronavirus disease 2019 (COVID-19) is characterized by an exaggerated inflammatory response mediated by an excessive production of interleukin-6 (IL-6) and other pro-inflammatory cytokines [1]. The clinical success of several therapeutic approaches has served as a proof of concept for the involvement of this "cytokine storm" in the pathogenesis of respiratory deterioration and progression to ARDS (acute respiratory distress syndrome) in patients with
COVID-19. A number of comparative observational studies have suggested that in patients with severe or worsening SARS-CoV-2 (severe acute respiratory syndrome coronavirus 2) pulmonary disease, tocilizumab, a monoclonal antibody directed against the IL- 6 receptor, may decrease the need for mechanical ventilation and improve survival $[2,3]$. Moreover, in our clinical setting, a personalized treatment with selective IL- 6 and/or IL- 1 blockade based on the individual patterns of inflammatory markers was associated with better survival [4]. In addition, a randomized clinical trial has proved that dexamethasone reduces mortality in patients requiring respiratory support [5]. Among other inhibitors of specific cytokines or more general inflammatory pathways, anakinra may be effective in patients with severe pneumonia and a hyperinflammatory state [6-8], and baricitinib in combination with remdesivir improved the clinical status of patients with COVID-19, particularly those receiving high-flux oxygen or noninvasive ventilation [9].

Although the first concern that inflammatory response modifiers could worsen the prognosis of COVID-19 by increasing viral replication or persistence has been mitigated by clinical experience, the possibility that they may still increase the rate of hospital-acquired infection has not been completely discarded [10-14]. The aim of the present study was to investigate the possible influence of the administration of inflammatory response modifiers, including anti-IL- 6 biologics and corticosteroids, on the incidence of hospitalacquired infections in admitted patients with COVID-19.

\section{METHODS}

This is a case-control study performed with data retrieved from a specifically created database during the COVID-19 epidemic at a 750-bed university hospital in Barcelona (Spain). The study period was between February 26 and May 26, 2020. Cases were defined as patients with COVID-19 acquiring an infection during their hospital stay. Diagnosis of COVID-19 was based on a positive RT-PCR in a nasopharyngeal 
swab or lower respiratory secretions. For each case, two controls were selected among patients with COVID-19 who did not acquire any infection. Three matching criteria were used in a hierarchical sequence. All controls must have had a length of hospital stay at least equal to the time elapsed from admission to the date of the first nosocomial infection in cases (equal or higher time at risk). After fulfilling this requirement, they were matched, if feasible, for the presence of any comorbidity and lastly for the need for ICU admission. To proceed with the selection, patients and controls were listed in an ascending order of time at risk and then for each consecutive case; the two closest controls fulfilling the time at risk and then the other matching criteria were chosen.

Hospital-acquired infections were defined according to the Centers for Disease Control and Prevention (CDC) criteria [15]. For ventilator-associated tracheobronchitis (VAT), the definition proposed by Craven et al. was used [16]. Only microbiologically documented infections deserving directed antibiotic therapy at the attending physician's discretion were included. Exposures had to be present for at least $24 \mathrm{~h}$ before the onset of infection. According to the local protocol, tocilizumab was administered as two doses of $400-600 \mathrm{mg} /$ $12 \mathrm{~h}$ apart with the option for a third dose $24 \mathrm{~h}$ later if there was progression of respiratory failure; however, at some point during the epidemic, only a single dose of $400 \mathrm{mg}$ could be used because of shortages. Siltuximab and sarilumab were administered as single doses of $11 \mathrm{mg} / \mathrm{kg}$ and $200 \mathrm{mg}$, respectively. Anakinra was given as $200 \mathrm{mg} / 12 \mathrm{~h}$ up to 5 days and baricitinib as $4 \mathrm{mg} /$ day for 10 days. In regards to corticosteroids, the local protocol recommended methylprednisolone $1 \mathrm{mg} / \mathrm{kg} /$ day to a maximum of $250 \mathrm{mg} /$ day for 3 days followed by $0.5 \mathrm{mg} / \mathrm{kg}$ for three additional days. However, other schedules like prednisone $1-2 \mathrm{mg} / \mathrm{kg} /$ day, dexamethasone $6 \mathrm{mg} / \mathrm{kg} /$ day, or hydroxycortisone $100-400 \mathrm{mg} /$ day for 10 days were also used at the discretion of the attending physician. Some patients continued treatment with lower doses of prednisone for longer periods as therapy for organizing pneumonia.
Assessed variables included demographics (age and sex), comorbidities, ICU admission, invasive and non-invasive mechanical ventilation, use of any medication (lopinavir-ritonavir, hydroxychloroquine, azithromycin, interferon- $\beta$, tocilizumab, other anti-IL-6 agents, baricitinib, anakinra, corticosteroids, antibiotics, and vasopressors), site of infection, and involved microorganisms in infected patients. Unfortunately, exposure to intravenous and urinary catheters was not recorded.

The median and the first and third quartiles were the measures of central tendency and dispersion displayed in this study, respectively. For univariate analysis, comparisons of continuous variables were performed by using the $t$ test or Mann-Whitney $U$ test depending on whether a normal distribution could be assumed or not. Categorical variables were compared by the chisquared test or Fisher exact test when necessary. In order to assess the independent association of clinical characteristics and exposures with being a case, multivariate analysis was performed by using a conditional logistic regression procedure. In multivariate analysis, only variables with a univariate $p$ value $<0.2$ were allowed to enter the model and further selection was done by a stepwise backward procedure with a $p$ value to step in and out of the model of 0.05. Calculations were done by using version 22 of the SPSS statistical package.

\section{Compliance with Ethics Guidelines}

The Institutional Ethics Committee of the Hospital Clinic of Barcelona approved the study and, owing to the nature of retrospective chart review, waived the need for inform consent from individual patients (HCB/2020/0273).

\section{RESULTS}

During the study period, 109 hospital-acquired infections were diagnosed in 71 patients. A single infection developed in 41 (57.7\%) patients, two in $22(30.9 \%)$, and three in 8 $(11.2 \%)$. The most common infection was ventilator-associated tracheobronchitis $(n=33$, $30.2 \%$ ) followed by urinary tract infection 
( $n=29,26.6 \%)$, catheter-related bloodstream infection $(n=24,22 \%)$, ventilator-associated pneumonia $(n=15,13.7 \%)$, and others $(n=8$, $7.3 \%)$. Median days from hospital admission to administration of tocilizumab, anakinra, and corticosteroids were $2(0-4), 4$ (1.75-8.75), and 2 $(0-5)$, respectively, without significant differences between cases and controls. In case patients, median times elapsed from the onset of tocilizumab, anakinra, and corticosteroids to infection were 10 days (7-19), 8 days (3.75-21.75), and 10 days (6.75-17.25), respectively. Sixty-three patients $(88.7 \%)$ were in ICU when the first hospital infection was diagnosed. In these patients, median time to ICU admission was 0 days ( $0-2$ days) and that from ICU admission to the first nosocomial infection was 10 days (7-19 days). Sixteen (22.5\%) cases and 33 (23.2\%) controls died in hospital (OR 0.96, $95 \%$ CI $0.48-1.89, p=0.9)$. Table 1 shows the etiological microorganisms of the different hospital-acquired infections.

Among infected patients, the median number of infections was 1 (1-2) regardless of whether they received biologics or corticosteroids. The comparative frequencies of clinical characteristics and exposures in cases and controls with their corresponding measurements of association are shown in Table 2 . Cases were more likely than controls to be older, to have been transferred from another hospital, to have a history of alcohol abuse, to have ARDS, and to have been exposed to interferon- $\beta$, multiple antibiotics, ICU, vasopressors, and invasive mechanical ventilation. Chronic liver disease $(p=0.068)$ and morbid obesity $(p=0.066)$ were numerically more frequent in cases than controls, while cases shown a non-significant trend to be less exposed to hydroxychloroquine $(p=0.079)$. The median time at risk was 11 days. As expected from the procedure used for the selection of controls, significantly more patients in this group have a time at risk longer than the median.

Multivariate analysis selected the following as the best predictors for acquiring a nosocomial infection: chronic liver disease (OR 16.56, 95\% CI 1.87-146.5, $p=0.012$ ), morbid obesity (OR $6.11,95 \%$ CI $1.06-35.4, p=0.043)$, current or past smoking (OR 4.15, 95\% CI 1.45-11.88, $p=0.008)$, exposure to hydroxychloroquine (OR $0.2,95 \%$ CI $0.041-1, p=0.053$ ), and invasive mechanical ventilation (OR 61.5, 95\% CI $11.08-341, p \leq 0.0001)$.

In $19(26.7 \%)$ cases, a fungal species was involved, Candida spp. in 16, Aspergillus fumigatus in two, and Fusarium spp. in one. Of these, eight were unequivocally invasive (six episodes of catheter-related candidemia and two probable ventilator-associated pneumonia (VAP) due to filamentous fungi). However, when compared with controls, no association was found between having a fungal infection and exposure to tocilizumab (OR 0.81, 95\% CI 0.28-2.39, $p=0.71$ ), to any anti-IL-6 biologic (OR 0.53, 95\% CI 0.17-1.6, $p=0.26$ ), to corticosteroids (OR $0.84,95 \%$ CI $0.21-3.33, p=0.81$ ), to biologics or corticosteroids (OR $0.17,95 \%$ CI $0.01-1.6, p=0.12$ ), or to biologics plus corticosteroids (OR 0.7, 95\% CI 0.22-2.23, $p=0.55$ ). Exposure to high dose of either tocilizumab (>600 mg) or a very high dose of corticosteroids ( $\geq 200 \mathrm{mg}$ of prednisone equivalent) was not significantly different in cases and controls (OR 1.42, 95\% CI 0.45-4.5, $p=0.54$ for high-dose tocilizumab; OR $0.34,95 \%$ CI 0.93-1.28, $\quad p=0.11$ for high-dose corticosteroids).

\section{DISCUSSION}

The main result of the present study is that there is no evidence of any deleterious influence of inflammatory response modifiers on the incidence of hospital-acquired infection in admitted patients with SARS-CoV-2 infection. In our experience, nosocomial infections in patients with COVID-19 primarily occurred in the critically ill, and mechanical ventilation was the only significant exposure conferring risk.

Data comparing the incidence of nosocomial infections in patients with severe COVID-19 between those taking and not taking inflammatory response modifies are relatively scarce. Several comparative retrospective studies have described a higher rate of infections in patients receiving tocilizumab than in controls. Somers et al. [10] observed a significantly increased rate of superinfection in treated patients $(54 \%$ vs 
Table 1 Microorganisms involved in 109 episodes of hospital-acquired infections in 71 hospitalized patients with COVID-19

\begin{tabular}{|c|c|c|c|c|c|}
\hline Microorganism & VAP & VAT & $\begin{array}{l}\text { Catheter-related } \\
\text { bacteremia }\end{array}$ & $\begin{array}{l}\text { Urinary tract } \\
\text { infection }\end{array}$ & Other \\
\hline Gram-positives & 1 & 4 & 15 & 5 & 6 \\
\hline $\begin{array}{l}\text { Methicillin-susceptible Staphylococcus } \\
\text { aureus }\end{array}$ & 1 & 4 & - & - & - \\
\hline Methicillin-resistant $S$. aureus & - & - & - & - & - \\
\hline Coagulase-negative staphylococci & - & - & 10 & - & - \\
\hline Streptococcus anginosus & - & - & 1 & - & - \\
\hline Enterococcus faecalis & - & - & 3 & 4 & 1 \\
\hline Enterococcus faecium & & - & 1 & 1 & \\
\hline Clostridioides difficile & - & - & - & - & 2 \\
\hline Gram-negatives & 12 & 21 & 3 & 21 & 0 \\
\hline Escherichia coli & - & - & - & 3 & - \\
\hline ESBL-producing E. coli & - & - & - & 3 & - \\
\hline Klebsiella pneumoniae & - & 2 & 1 & - & - \\
\hline ESBL-producing $K$. pneumoniae & 1 & - & - & 2 & - \\
\hline Klebsiella oxytoca & 1 & - & - & - & - \\
\hline Proteus mirabilis & - & - & - & 1 & - \\
\hline Enterobacter cloacae & 2 & 2 & 2 & - & - \\
\hline Klebsiella aerogenes & 2 & 1 & - & - & - \\
\hline Citrobacter spp. & - & - & - & 1 & - \\
\hline Serratia marcescens & 1 & 3 & - & - & - \\
\hline $\begin{array}{l}\text { Carbapenemase-producing } \\
\text { Enterobacterales }\end{array}$ & - & - & - & 1 & - \\
\hline Non-MDR Pseudomonas aeruginosa & 3 & 4 & - & 10 & - \\
\hline MDR $P$. aeruginosa & 1 & 2 & - & - & - \\
\hline Stenotrophomonas maltophilia & 1 & 4 & - & - & - \\
\hline Burkholderia gladioli & & 2 & - & - & - \\
\hline Bordetella spp. & & 1 & - & - & - \\
\hline Fungi & 2 & 4 & 6 & 7 & 2 \\
\hline Candida spp. & & 3 & 6 & 7 & 2 \\
\hline Aspergillus spp. & 1 & 1 & - & - & - \\
\hline
\end{tabular}


Table 1 continued

\begin{tabular}{lllll}
\hline Microorganism & VAP & VAT & $\begin{array}{l}\text { Catheter-related } \\
\text { bacteremia }\end{array}$ & $\begin{array}{l}\text { Urinary tract } \\
\text { infection }\end{array}$ \\
\hline Fusarium spp. & 1 & - & - & - \\
\hline
\end{tabular}

$V A P$ ventilator-associated pneumonia, $V A T$ ventilator-associated tracheobronchitis, $E S B L$ extended-spectrum beta-lactamase, $M D R$ multidrug-resistant

$26 \%$; $p<0.001)$, mostly due to a higher incidence of VAP. However, no difference between groups with regards to the frequency of bloodstream infections or development of more than one infection was observed. Guaraldi et al. [11] also observed an increased rate of hospital-acquired infections in patients treated with tocilizumab versus those in the standard of care group (13\% vs $4 \%, p>0.001)$, including four cases of invasive aspergillosis in the tocilizumab group and none in the standard of care. Kimmig et al. [12] reported a higher incidence of bacterial infections in patients receiving tocilizumab (adjusted OR 2.76, 95\% CI 1.11-7.2), with all fungal infections occurring in the actively treated group. Lewis et al. [13], in a propensitymatched cohort study, also found an increased adjusted rate of secondary infections (OR 4.18, 95\% CI 2.72-6.52) due to a higher incidence of bloodstream infections, pneumonia, and urinary tract infections. Lastly, Pettit et al. [14] reported an increased rate of late-onset infections in patients receiving tocilizumab (23\% vs $8 \%, p=0.013)$. Conversely, a higher rate of infections in patients taking tocilizumab was not observed in 14 prospective studies, including eight randomized controlled trials $[2,3,8,17-22]$. The reasons for these discrepancies are not clear, but it can be speculated that the survival benefit associated with tocilizumab in several retrospective studies $[10,11,13]$ could actually have prolonged the time at risk in this population and therefore the likelihood of getting an infection.

Our data suggests that when time at risk and other general predisposing factors (presence of any comorbidity and need for ICU admission) are similar between infected and not infected patients, no evidence of an increased risk of infection associated with exposure to biologics can be found. This also agrees with the lack of evidence of a higher risk of infection associated with a short (1-3 doses) exposure to tocilizumab in severely immunosuppressed patients with chimeric antigen receptor (CART) T cell-mediated cytokine release syndrome [23].

Data regarding other interleukin blockers are still sparser. Although IL-1 inhibitors (anakinra), like IL-6 blockers, have been associated with an increased rate of usually mild to moderate infection in the long-term treated patients with rheumatoid arthritis, no such increase has been observed with short-course regimens used for the therapy of patients with COVID-19 [6, 8] or of those with gout or sepsis [24, 25]. Lastly, in regards to corticosteroids, it is of note that despite their downregulation effect on the synthesis of pro-inflammatory cytokines and on the function of virtually any cell involved in the sensing of or response to invading microorganisms [26], their role as a risk factor for superinfection following short-term exposure is probably negligible. Several randomized clinical trials have assessed the therapeutic role of corticosteroids on COVID-19, and none of them reported a significantly higher incidence of superinfections in actively treated patients $[5,27-30]$. This agrees with many randomized clinical trials conducted to evaluate the effect of acute exposure to corticosteroids on patients with sepsis or ARDS. The summarized evidence from these trials indicates that there is no association of corticosteroids with superinfection, regardless of the type of drug or specific regimen [31-33].

The present study suggests a possible protective effect of hydroxychloroquine on the acquisition of hospital-acquired infections, although the variable was retained in the multivariate model with borderline significance. 
Table 2 Comparative prevalence of evaluated clinical characteristics and exposures in cases and controls (univariate analysis)

\begin{tabular}{|c|c|c|c|c|}
\hline Characteristic or exposure & $\begin{array}{l}\text { Controls } \\
(n=142) \\
(\%)\end{array}$ & $\begin{array}{l}\text { Cases } \\
(n=71) \\
(\%)\end{array}$ & OR $(95 \% \mathrm{CI})^{\mathrm{a}}$ & $p^{\mathrm{a}}$ \\
\hline Age $>65$ & $62(43.7)$ & $42(59.2)$ & $2(1.08-3.67)$ & 0.024 \\
\hline Male sex & $101(71.1)$ & $48(67.6)$ & $1.16(0.64-2.11)$ & 0.61 \\
\hline Transfer from other hospital & $15(10.6)$ & $15(21.1)$ & $2.19(1.01-4.75)$ & 0.046 \\
\hline Any comorbidity & $129(90.9)$ & $65(91.5)$ & $1.44(0.18-11.1)$ & 0.72 \\
\hline Chronic pulmonary disease & $26(18)$ & $15(21.1)$ & $1.18(0.59-2.36)$ & 0.63 \\
\hline Diabetes & $28(19.7)$ & $12(16.9)$ & $0.82(0.38-1.76)$ & 0.61 \\
\hline Hypertension & $76(53.5)$ & $39(54.9)$ & $1.06(0.58-1.91)$ & 0.84 \\
\hline Heart disease & $32(22.5)$ & $15(21.1)$ & $0.91(0.44-1.8)$ & 0.8 \\
\hline Cerebrovascular disease & $10(7)$ & $4(5.6)$ & $0.8(0.25-2.55)$ & 0.7 \\
\hline HIV infection & $3(2.1)$ & $1(1.4)$ & $0.66(0.06-6.4)$ & 0.72 \\
\hline Chronic renal insufficiency & $19(13.4)$ & $10(14.1)$ & $1.06(0.46-2.4)$ & 0.88 \\
\hline Chronic liver disease & $5(3.5)$ & $7(9.9)$ & $3.17(0.91-11)$ & 0.068 \\
\hline Solid organ cancer & $12(8.5)$ & $6(8.5)$ & $1(0.35-2.82)$ & 1 \\
\hline Haematological cancer & $9(6.3)$ & $1(1.4)$ & $0.22(0.02-1.7)$ & 0.15 \\
\hline Solid organ transplantation & $8(5.6)$ & $2(2.8)$ & $0.46(0.09-2.34)$ & 0.35 \\
\hline Autoimmune disease & $2(1.4)$ & $3(4.2)$ & $3(0.5-17.9)$ & 0.23 \\
\hline Immunosuppressors & $16(11.3)$ & $6(8.5)$ & $0.71(0.26-1.95)$ & 0.51 \\
\hline Morbid obesity & $9(6.3)$ & $10(14.1)$ & $2.5(0.93-6.67)$ & 0.066 \\
\hline Past or current smoking & $44(31)$ & $30(42.2)$ & $1.31(0.9-1.83)$ & 0.1 \\
\hline Alcohol abuse & $3(2.1)$ & $7(9.9)$ & $6.3(1.29-30.7)$ & 0.023 \\
\hline Lymphocyte count $<700$ cells $/ \mu \mathrm{L}$ & $70(49.3)$ & $40(56.3)$ & $1.32(0.74-2.35)$ & 0.33 \\
\hline Tocilizumab & $85(59.9)$ & $36(50.7)$ & $0.67(0.36-1.22)$ & 0.19 \\
\hline High-dose tocilizumab & $18(12.7)$ & $9(12.7)$ & $1(0.4-2.29)$ & 1 \\
\hline Siltuximab & $5(3.5)$ & $5(7)$ & $2.19(0.57-8.36)$ & 0.24 \\
\hline Sarilumab & $2(1.4)$ & - & $0.026(0-5748)$ & 0.56 \\
\hline Any anti-IL6 & $92(64.8)$ & $41(57.7)$ & $0.73(0.4-1.33)$ & 0.3 \\
\hline Anakinra (\%) & $38(26.8)$ & $14(19.7)$ & $0.68(0.35-1.34)$ & 0.27 \\
\hline Baricitinib & $3(0.42)$ & - & $0.026(0-601)$ & 0.47 \\
\hline Corticosteroids & $105(73.9)$ & $51(71.8)$ & $0.87(0.41-1.8)$ & 0.7 \\
\hline High-dose corticosteroids & $49(34.5)$ & $16(22.5)$ & $0.53(0.27-1.06)$ & 0.07 \\
\hline
\end{tabular}


Table 2 continued

\begin{tabular}{|c|c|c|c|c|}
\hline Characteristic or exposure & $\begin{array}{l}\text { Controls } \\
(n=142) \\
(\%)\end{array}$ & $\begin{array}{l}\text { Cases } \\
(n=71) \\
(\%)\end{array}$ & OR $(95 \% \mathrm{CI})^{\mathrm{a}}$ & $p^{\mathbf{a}}$ \\
\hline Lopinavir-ritonavir & $130(91.5)$ & $64(90.1)$ & $0.82(0.28-2.34)$ & 0.71 \\
\hline Hydroxychloroquine & $137(96.5)$ & $64(90.1)$ & $0.35(0.1-1.12)$ & 0.079 \\
\hline Remdesivir & $12(8.5)$ & $5(7)$ & $0.82(0.28-2.41)$ & 0.72 \\
\hline Interferon- $\beta$ & $35(24.6)$ & $30(42.3)$ & $2.17(1.19-3.9)$ & 0.01 \\
\hline Azithromycin & $119(83.8)$ & $53(76.6)$ & $0.59(0.3-1.16)$ & 0.12 \\
\hline Any other antibiotic & $119(83.8)$ & $61(85.9)$ & $1.17(0.53-2.57)$ & 0.69 \\
\hline$\geq 2$ antibiotics & $75(52.8)$ & $47(66.2)$ & $1.84(0.98-3.45)$ & 0.058 \\
\hline$\geq 3$ antibiotics & $36(25.4)$ & $24(33.8)$ & $1.47(0.8-2.72)$ & 0.2 \\
\hline$\geq 4$ antibiotics & $5(3.5)$ & $7(9.9)$ & $3.78(0.95-15)$ & 0.059 \\
\hline $\mathrm{ICU}$ & $115(81)$ & $63(88.7)$ & $5.92(1.21-28.8)$ & 0.027 \\
\hline Vasopressors & $48(33.8)$ & $51(71.8)$ & $6.63(3.07-14.4)$ & $<0.0001$ \\
\hline Invasive mechanical ventilation & $39(27.5)$ & $56(78.9)$ & $16.1(5.77-45.2)$ & $<0.0001$ \\
\hline Non-invasive mechanical ventilation & $22(15.5)$ & $6(8.5)$ & $0.48(0.18-1.31)$ & 0.15 \\
\hline ARDS & $102(71.8)$ & $60(84.5)$ & $2.21(1.03-4.74)$ & 0.04 \\
\hline Statins & $15(10.6)$ & $10(14.1)$ & $1.35(0.59-3.06)$ & 0.47 \\
\hline Days at risk $\geq 11$ days & $110(77.5)$ & $41(57.7)$ & $0.21(0.08-0.5)$ & $<0.0001$ \\
\hline
\end{tabular}

a $\mathrm{OR}, 95 \% \mathrm{CI}$, and $p$ values estimated by conditional logistic regression analysis

This finding is intriguing and difficult to explain. Hydroxychloroquine accumulates in the lysosomes and other cellular organelles and neutralizes their acidic $\mathrm{pH}$. This property endows the drug with in vitro activity against many viruses, as well as bacteria and fungi located in the appropriate intracellular environment, where a synergistic effect with several antimicrobial agents may occur [34]. However, in the clinical setting, hydroxychloroquine combined with appropriate antibiotics has proved to be critically effective only for the treatment of Q fever and Whipple disease. Actually, after much initial discussion and several randomized clinical trials, hydroxychloroquine has proved to be ineffective for both prevention and treatment of COVID-19 [35]. We cannot discard that the association of less hydroxychloroquine exposure with acquisition of nosocomial infections observed in our study stemmed from a possible more severe condition of case patients.

The present study was intended to assess the possible influence of inflammation-response modifiers on the rate of hospital-acquired infections, not to evaluate the relative incidence of nosocomial infection in patients with SARS-CoV-2. Currently, there is no definitive answer to this issue, due mainly to a substantial lack of comparative data between patients with COVID-19 and appropriate controls without SARS-CoV-2 infection [36-40]. The available evidence suggests that patients with COVID-19 do not seem to be particularly prone to acquire nosocomial bacterial infections or invasive candidiasis. However, an increased incidence of 
invasive aspergillosis among intubated patients with COVID-19 cannot be completely dismissed $[41,42]$.

Our study has the common drawbacks of being relatively small, unicentric, and observational. In addition, matching was not wholly successful, exposure to intravenous and urinary catheters was not documented, and the duration of exposure to inflammatory response modifiers was not systematically registered. Moreover, we limited follow-up to the length of hospital stay; hence late-onset infections possibly related to past exposure to biologics or corticosteroids, such as tuberculosis, were not assessed. A last concerning issue is the possibility of misclassification bias of true bacterial or fungal infections, particularly those of pulmonary location, by using common clinical or radiological surveillance criteria in a population already overwhelmed with basal and evolving radiological chest abnormalities and high inflammatory markers. We tried to retain diagnostic specificity by including the requirement of microbiological documentation and directed antibiotic therapy as additional criteria to ascertain cases and distinguish them from controls.

\section{CONCLUSIONS}

Acute exposure of patients with severe COVID19 to inflammatory response modifiers, including IL-6 blockers and corticosteroids, does not seem to increase the risk of acquiring a nosocomial infection beyond that expected in unexposed patients with SARS-CoV-2 infection of similar severity.

\section{ACKNOWLEDGEMENTS}

We would like to thank Gerard Dueñas, Berta Folguera, Pablo Sierra, Joan Company, Marina Buenechea, Pau Baselga, and Antonio Jiménez. All the personnel of the Infectious Diseases Department and the Department of International Health. COVID-19 Researchers: Catia Cilloniz, Lorna Leal, Berta Torres, Alexy Inciarte, Lorena de La Mora, Ana González, Jhon
Rojas, Berta Fidalgo, Natalia Rodriguez, David Nicolas, José Muñoz, Alex Almuedo, Daniel Camprubí, $\mathrm{M}^{\mathrm{a}}$ Angeles Marcos, Mariana Fernandez-Pittol, Adrian Téllez , Monste Sola, Montse Laguno, Antonio Moreno, Sara Fernández, Pedro Castro, Antoni Torres, Jose M Nicolas, Felipe Garcia and Josep Mensa.

Funding. This work was supported by a crowdfunding obtained by Hospital Clinic IDIBAPS. EM-G [PI18/01061], PP-A [CM18/ 00132], NG-P [FI19/00133], and CG-V [FIS PI18/ 01061] have received research grants from the Ministerio de Sanidad y Consumo, Instituto de Salud Carlos III. No funding bodies had any role in study design, data collection and analysis, decision to publish or preparation of the manuscript. No sponsorship or funding was received for the publication of this article.

Medical Writing Assistance. Anthony Armenta, an independent corrector, provided medical writing support, which was funded by MSD (Merck Sharp \& Dohme). MSD was not involved in the content of the manuscript.

Authorship. All named authors meet the International Committee of Medical Journal Editors (ICMJE) criteria for authorship for this article, take responsibility for the integrity of the work as a whole, and have given their approval for this version to be published.

Authorship Contributions. Fernanda Meira; Estela Moreno-García; Laura Linares; José Antonio Martínez: Conceived the idea; design of the study, data collection; statistical analysis; interpretation and writing the manuscript. Irene Macaya; Adria Tomé; Marta HernándezMeneses; Laia Albiach; Laura Morata; Laura Letona; Marta Bodro; Alberto Cózar-Llistó; Celia Cardozo; Mariana Chumbita; Cristina Pitart; Juan Ambrosioni; Verónica Rico; Daiana Agüero; Pedro Puerta-Alcalde; Nicole GarciaPouton; Francesc Marco; Carolina Garcia-Vidal: data collection, interpretation and revisión of the manuscript. Alex Soriano: Conceived the idea; design of the study, data collection; statistical analysis; interpretation and writing the manuscript. 
Disclosures. Estela Moreno-García reports grant from Instituto de Salud Carlos III, outside the submitted work. Marta Hernández-Meneses reports grants from Instituto de Salud Carlos III, outside the submitted work. Nicole GarciaPouton reports grants from Instituto de Salud Carlos III, outside the submitted work. Pedro Puerta-Alcalde reports grants from Instituto de Salud Carlos III, and personal fees from Gilead S.A. and Pfizer S.A., outside the submitted work. Carolina Garcia-Vidal has received honoraria for talks on behalf of Gilead Science, MSD, Novartis, Pfizer, Jannsen, Angellini, Lilly as well as grants from Gilead Science, EIT Health, Instituto de Salud Carlos III, and MSD. Alex Soriano has received honoraria for lectures and advisory boards for Pfizer, Merck Sharp and Dohme, Menarini, shionogi, Angellini and Gilead. Alex Soriano is also the journal's coEditor-in-Chief. Juan Ambrosioni is a member of the journal's Editorial Board. Fernanda Meira; Estela Moreno-García; Laura Linares; José Antonio Martínez; Irene Macaya; Adria Tomé; Laia Albiach; Laura Morata; Laura Letona; Marta Bodro; Alberto Cózar-Llistó; Celia Cardozo; Mariana Chumbita; Cristina Pitart; Juan Ambrosioni; Verónica Rico; Daiana Agüero; Francesc Marco; had no potential conflicts of interest. No funding bodies had any role in study design, data collection and analysis, decision to publish or preparation of the manuscript.

Compliance with Ethics Guidelines. The Institutional Ethics Committee of the Hospital Clinic of Barcelona approved the study and, owing to the nature of retrospective chart review, waived the need for inform consent from individual patients (HCB/2020/0273).

Data Availability. The datasets generated during and/or analyzed during the current study are available from the corresponding author on reasonable request.

\section{REFERENCES}

1. Magro G. COVID-19: review on latest available drugs and therapies against SARS-CoV-2. Coagulation and inflammation cross-talking. Virus Res. 2020;286:198070. virusres.2020.198070

2. Salama C, Han J, Yau L, et al. Tocilizumab in patients hospitalized with Covid-19 pneumonia. N Engl J Med. 2021;384(1):20-30. https://doi.org/ 10.1056/NEJMoa2030340.

3. REMAP-CAP Investigators, Gordon AC, Mouncey $\mathrm{PR}, \mathrm{Al}-\mathrm{Beidh} \mathrm{F}$, et al. Interleukin-6 receptor antagonists in critically ill patients with Covid-19. N Engl J Med. 2021. https://doi.org/10.1056/ NEJMoa2100433.

4. Garcia-Vidal C, Moreno-García E, Hernández-Meneses $\mathrm{M}$, et al. Personalized therapy approach for hospitalized patients with COVID-19. Clin Infect Dis. 2020. https://doi.org/10.1093/cid/ciaa964.

5. RECOVERY Collaborative Group, Horby P, Lim WS, Emberson JR, et al. Dexamethasone in hospitalized patients with Covid-19. N Engl J Med. 2021;384(8): 693-704. https://doi.org/10.1056/NEJMoa2021436.

6. CORIMUNO-19 Collaborative Group. Effect of anakinra versus usual care in adults in hospital with COVID-19 and mild-to-moderate pneumonia (CORIMUNO-ANA-1): a randomised controlled trial. Lancet Respir Med. 2021;9(3):295-304. https://doi.org/10.1016/S2213-2600(20)30556-7.

7. Cavalli G, Dagna L. The right place for IL-1 inhibition in COVID-19. Lancet Respir Med. 2021;9(3): 223-4. 2600(21)00035-7. https://doi.org/10.1016/S2213-

8. Khan FA, Stewart I, Fabbri L, et al. Systematic review and meta-analysis of anakinra, sarilumab, siltuximab and tocilizumab for COVID-19. Thorax. 2021. https://doi.org/10.1136/thoraxjnl-2020-215266.

9. Kalil AC, Patterson TF, Mehta AK, et al. Baricitinib plus remdesivir for hospitalized adults with Covid19. N Engl J Med. 2021;384(9):795-807. https://doi. org/10.1056/NEJMoa2031994.

10. Somers EC, Eschenauer GA, Troost JP, et al. Tocilizumab for treatment of mechanically ventilated patients with COVID-19. Clin Infect Dis. 2020. https://doi.org/10.1093/cid/ciaa954.

11. Guaraldi G, Meschiari M, Cozzi-Lepri A, et al. Tocilizumab in patients with severe COVID-19: a retrospective cohort study. Lancet Rheumatol. 2020;2(8):e474-84. https://doi.org/10.1016/S26659913(20)30173-9. 
12. Kimmig LM, Wu D, Gold M, et al. IL-6 inhibition in critically ill COVID-19 patients is associated with increased secondary infections. Front Med (Lausanne). 2020;28(7):583897. https://doi.org/10. 3389/fmed.2020.583897.

13. Lewis TC, Adhikari S, Tatapudi V, et al. A propensity-matched cohort study of tocilizumab in patients with coronavirus disease 2019. Crit Care Explor. 2020;2(11):e0283. https://doi.org/10.1097/ CCE.0000000000000283.

14. Pettit NN, Nguyen CT, Mutlu GM, et al. Late onset infectious complications and safety of tocilizumab in the management of COVID-19. J Med Virol. 2021;93(3):1459-64. https://doi.org/10.1002/jmv. 26429.

15. Garner JS, Jarvis WR, Emori TG, Horan TC, Hughes JM. CDC definitions for nosocomial infections, 1988. Am J Infect Control. 1988;16(3):128-40. https://doi.org/10.1016/0196-6553(88)90053-3.

16. Craven DE, Chroneou A, Zias N, Hjalmarson KI. Ventilator-associated tracheobronchitis: the impact of targeted antibiotic therapy on patient outcomes. Chest. 2009;135(2):521-8. https://doi.org/10.1378/ chest.08-1617.

17. Stone JH, Frigault MJ, Serling-Boyd NJ, et al. Efficacy of tocilizumab in patients hospitalized with Covid-19. N Engl J Med. 2020;383(24):2333-44. https://doi.org/10.1056/NEJMoa2028836.

18. Salvarani C, Dolci G, Massari M, et al. Effect of tocilizumab vs standard care on clinical worsening in patients hospitalized with COVID-19 pneumonia: a randomized clinical trial. JAMA Intern Med. 2021;181(1):24-31. https://doi.org/10.1001/ jamainternmed.2020.6615.

19. Hermine O, Mariette $X$, Tharaux PL, et al. Effect of tocilizumab vs usual care in adults hospitalized with COVID-19 and moderate or severe pneumonia: a randomized clinical trial. JAMA Intern Med. 2021;181(1):32-40. https://doi.org/10.1001/ jamainternmed.2020.6820.

20. Rosas IO, Bräu N, Waters M, et al. Tocilizumab in hospitalized patients with severe COVID-19 pneumonia. N Engl J Med. 2021. https://doi.org/10. 1056/NEJMoa2028700.

21. Wang D, Fu B, Peng Z, et al. Tocilizumab in patients with moderate or severe COVID-19: a randomized, controlled, open-label, multicenter trial. Front Med. 2021;9:1-9. https://doi.org/10.1007/s11684020-0824-3.

22. Veiga VC, Prats JAGG, Farias DLC, et al. Effect of tocilizumab on clinical outcomes at 15 days in patients with severe or critical coronavirus disease
2019: randomised controlled trial. BMJ. 2021;20(372):n84. https://doi.org/10.1136/bmj. n84.

23. Frigault MJ, Nikiforow S, Mansour MK, et al. Tocilizumab not associated with increased infection risk after CAR T-cell therapy: implications for COVID19? Blood. 2020;136(1):137-9. https://doi.org/10. 1182/blood.2020006216.

24. Winthrop KL, Mariette X, Silva JT, et al. ESCMID Study Group for Infections in Compromised Hosts (ESGICH) Consensus Document on the safety of targeted and biological therapies: an infectious diseases perspective (Soluble immune effector molecules [II]: agents targeting interleukins, immunoglobulins and complement factors). Clin Microbiol Infect. 2018;24(Suppl 2):S21-40. https:// doi.org/10.1016/j.cmi.2018.02.002.

25. Opal SM, Fisher CJ Jr, Dhainaut JF, et al. Confirmatory interleukin-1 receptor antagonist trial in severe sepsis: a phase III, randomized, double-blind, placebo-controlled, multicenter trial. The Interleukin-1 Receptor Antagonist Sepsis Investigator Group. Crit Care Med. 1997;25(7):1115-24. https:// doi.org/10.1097/00003246-199707000-00010.

26. Heming N, Sivanandamoorthy S, Meng P, Bounab $\mathrm{R}$, Annane D. Immune effects of corticosteroids in sepsis. Front Immunol. 2018;9:1736. https://doi. org/10.3389/fimmu.2018.01736.

27. Jeronimo CMP, Farias MEL, Val FFA, et al. Methylprednisolone as adjunctive therapy for patients hospitalized with COVID-19 (metcovid): a randomised, double-blind, phase IIb, placebo-controlled trial. Clin Infect Dis. 2020. https://doi.org/ 10.1093/cid/ciaa1177.

28. Angus DC, Derde L, Al-Beidh F, et al. Effect of hydrocortisone on mortality and organ support in patients with severe COVID-19: the REMAP-CAP COVID-19 corticosteroid domain randomized clinical trial. JAMA. 2020;324(13):1317-29. https://doi. org/10.1001/jama.2020.17022.

29. Dequin PF, Heming N, Meziani F, et al. Effect of hydrocortisone on 21-day mortality or respiratory support among critically ill patients with COVID19: a randomized clinical trial. JAMA. 2020;324(13): 1298-306. https://doi.org/10.1001/jama.2020. 16761.

30. Tomazini BM, Maia IS, Cavalcanti AB, et al. Effect of dexamethasone on days alive and ventilator-free in patients with moderate or severe acute respiratory distress syndrome and COVID-19: the CODEX randomized clinical trial. JAMA. 2020;324(13): 1307-16. https://doi.org/10.1001/jama.2020. 17021. 
31. Annane D, Bellissant E, Bollaert PE, et al. Corticosteroids for treating sepsis in children and adults. Cochrane Database Syst Rev. 2019;12(12): CD002243. https://doi.org/10.1002/14651858. CD002243.pub4.

32. Fang F, Zhang Y, Tang J, et al. Association of corticosteroid treatment with outcomes in adult patients with sepsis: a systematic review and metaanalysis. JAMA Intern Med. 2019;179(2):213-23. https://doi.org/10.1001/jamainternmed.2018.5849.

33. Zayed Y, Barbarawi M, Ismail E, et al. Use of glucocorticoids in patients with acute respiratory distress syndrome: a meta-analysis and trial sequential analysis. J Intensive Care. 2020;8:43. https://doi. org/10.1186/s40560-020-00464-1.

34. Rolain JM, Colson P, Raoult D. Recycling of chloroquine and its hydroxyl analogue to face bacterial, fungal and viral infections in the 21st century. Int J Antimicrob Agents. 2007;30(4): 297-308. https://doi.org/10.1016/j.ijantimicag. 2007.05.015.

35. Kumar J, Jain S, Meena J, Yadav A. Efficacy and safety of hydroxychloroquine/chloroquine against SARS-CoV-2 infection: a systematic review and meta-analysis. J Infect Chemother. 2021. https:// doi.org/10.1016/j.jiac.2021.02.021.

36. Rawson TM, Moore LSP, Zhu N, et al. Bacterial and fungal co-infection in individuals with coronavirus: a rapid review to support COVID-19 antimicrobial prescribing. Clin Infect Dis. 2020. https://doi.org/ 10.1093/cid/ciaa530.
37. Falcone M, Tiseo G, Giordano C, et al. Predictors of hospital-acquired bacterial and fungal superinfections in COVID-19: a prospective observational study. J Antimicrob Chemother. 2021;76(4): 1078-84. https://doi.org/10.1093/jac/dkaa530.

38. Hughes S, Troise O, Donaldson H, Mughal N, Moore LSP. Bacterial and fungal coinfection among hospitalized patients with COVID-19: a retrospective cohort study in a UK secondary-care setting. Clin Microbiol Infect. 2020;26(10):1395-9. https:// doi.org/10.1016/j.cmi.2020.06.025.

39. Karami Z, Knoop BT, Dofferhoff ASM, et al. Few bacterial co-infections but frequent empiric antibiotic use in the early phase of hospitalized patients with COVID-19: results from a multicentre retrospective cohort study in The Netherlands. Infect Dis (Lond). 2021;53(2):102-10. https://doi.org/10. $1080 / 23744235.2020 .1839672$.

40. Garcia-Vidal C, Sanjuan G, Moreno-García E, et al. Incidence of co-infections and superinfections in hospitalized patients with COVID-19: a retrospective cohort study. Clin Microbiol Infect. 2021;27(1): 83-8. https://doi.org/10.1016/j.cmi.2020.07.041.

41. Marr KA, Platt A, Tornheim JA, et al. Aspergillosis complicating severe coronavirus disease. Emerg Infect Dis. 2021;27(1):18-25. https://doi.org/10. 3201/eid2701.202896.

42. Lamoth F, Lewis RE, Walsh TJ, Kontoyiannis DP. Navigating the uncertainties of COVID-19 associated aspergillosis (CAPA): a comparison with influenza associated aspergillosis (IAPA). J Infect Dis. 2021. https://doi.org/10.1093/infdis/jiab163. 